\title{
Factors Affecting the Food Allergy Profile of Children From Schools in Hortaleza District, Madrid, Spain
}

\author{
Cabrera $\mathrm{M}^{1}$, Ortiz-Menéndez $\mathrm{JC}^{2}$, Garzón $\mathrm{B}^{3}$ \\ ${ }^{1}$ Consulta de Alergia, Hospital los Madroños, Brunete (Madrid), \\ Spain \\ ${ }^{2}$ Departamento de Sanidad, Distrito de Hortaleza, Ayuntamiento \\ de Madrid, I'M FINE Research Group, Madrid, Spain \\ ${ }^{3}$ Unidad de Estadística, Secretaría Adjunta de Informática, \\ Consejo Superior de Investigaciones Cientificas (CSIC), Madrid, \\ Spain
}

J Investig Allergol Clin Immunol 2019; Vol. 29(1): 60-62 doi: $10.18176 /$ jiaci.0330

Key words: Food allergy. School canteens. Anaphylaxis. Epinephrine. Asthma. Polysensitization.

Palabras clave: Alergia a alimentos. Comedores escolares. Anafilaxia. Adrenalina. Asma. Polisensibilización.

We previously reported the prevalence of food allergenfree diets in school canteens in the Hortaleza district of Madrid, Spain [1]. Given the increased frequency of childhood food allergy, national and local policies have been developed to encourage school staff, families, and students to be aware of food allergy events. We have also described the use of epinephrine autoinjectors in this district [2].

The aim of this study was to analyze the food allergy profile and factors influencing food allergy in children from schools in Hortaleza district, Madrid.

A structured questionnaire on allergen-free diets based on a specialist report was administered in 49 schools in Hortaleza during the 2015-2016 school year ( $\mathrm{N}=1121$ children), after a letter was sent to all families by the school principals insisting on the importance of drawing up an action plan for children with food allergies. During the school year studied, 1069 students $(95.4 \%)$ were served allergen-free diets. The data recorded included sex, age, asthma history, type of school, presence or absence of polysensitization (sensitization to 2 or more food groups), and epinephrine prescription. From these schools, 251 children $(21.2 \%)$ had a food allergy action plan and 185 had been prescribed epinephrine $(72.1 \%$ of all those with an action plan and $15.6 \%$ of those with a reported food allergy). Nine of the children with an autoinjector were under 3 years old, 60 were between 3 and 5 years old, 104 were aged between 6 and 14 years, and 12 were 15 years or older. For students without an action plan, only the type of allergen-free diet they were on was noted. Frequencies were computed in February 2017. A Bonferroni correction was used to account for multiple comparisons (multiple comparisons of percentages). The relationship between food variables and epinephrine prescription were determined by cross-tabulation using a $\chi^{2}$ test and Monte Carlo estimation of exact $P$ values (SPSS, Version 24). 
Table. Main Features in Children's Food Allergy Profile for the School Year 2015-2016

\begin{tabular}{|c|c|c|c|c|}
\hline & $\begin{array}{c}\text { Children With } \\
\text { Epinephrine } \\
\text { Prescription, No. (\%) }\end{array}$ & $\begin{array}{l}\text { Children With Food } \\
\text { Allergy, No Epinephrine } \\
\text { Prescription vs Epinephrine } \\
\text { Prescription, No. }(\%)\end{array}$ & $\begin{array}{l}\text { Children With Food } \\
\text { Allergy and Epinephrine } \\
\text { Prescription, Asthma } \\
\text { vs No Asthma, } \\
\text { No. }(\%)\end{array}$ & $\begin{array}{l}\text { Children With Food } \\
\text { Allergy and Epinephrine } \\
\text { Prescription, Legumes } \\
\text { vs No Legumes, } \\
\text { No. (\%) }\end{array}$ \\
\hline$P$ Value $^{\mathrm{a}}$ & & .021 & .004 & .034 \\
\hline Without food allergy & $9(4.2 \%)$ & & & \\
\hline Monosensitized & $96(44.4 \%)$ & $81(50.9 \%)$ & $88(50.9 \%)$ & $95(52.8 \%)$ \\
\hline Polysensitized $^{\mathrm{b}}$ & $111(51.4 \%)$ & $33(68.8 \%)$ & $26(76.5 \%)$ & $26(96.3 \%)$ \\
\hline
\end{tabular}

aThe $P$ value corresponds to the $\chi^{2}$ statistic and is an exact Monte Carlo value.

${ }^{b}$ Food allergy to 2 distinct food groups was detected in $51.4 \%$ of the polysensitized children.

We evaluated 110 boys and 106 girls and found no differences in sensitization to the various food groups, although polysensitization was significant in boys $(P=.037)$. Epinephrine prescription and asthma history were also assessed. By age group, children under 6 years of age were more likely to be sensitized to egg and milk $(P<.000)$; of these, only 8 and 10 children under 3 years had egg and milk allergy, respectively. On the other hand, children aged over 6 years had allergy to fruits $(P=.032)$ and nuts $(P<.000)$. No differences were observed by age group in terms of epinephrine prescription, history of asthma, or presence of polysensitization.

We found that $68.75 \%$ of polysensitized children had been prescribed epinephrine $(P=.021,31.25 \%$ of monosensitized children) (Table). Moreover, $76.47 \%$ of the polysensitized children were asthmatic, compared with $23.53 \%$ of monosensitized children $(P=.004)$. Epinephrine prescription was associated with being asthmatic $(P<.0000)$ and polysensitization $(P=.034)$. Legumes were the only food group to show a significant relationship with epinephrine $(P=.025)$.

In children with food allergy to 2 different food groups (51.4\%), the most frequent food allergy combination for egg allergy was sensitization to milk and nuts. Other frequent combinations were nut and egg allergy, milk and egg allergy, and fruit and nut allergy.

As we previously reported [2], we will continue to reinforce food allergy notification in our health district. Hortaleza is the first large urban school district in Spain to develop and implement a food allergy survey, which has helped 185 students and school staff to avoid potential morbidity and mortality due to food allergy.

The many layers involved in the risk of severe reactions in food allergy include dose of allergen, age, timely effective treatment, coexistent allergy burden, and metabolic/ pharmacological factors, including exercise, illness, alcohol, and medications [3]. Fatal and severe reactions are more likely if there is a combination and alignment of risk factors [3].

In summary, we found that in children who had been prescribed epinephrine, allergy to more than 2 food groups was more likely to occur in asthmatic children than in children who are monosensitized, children who are not asthmatic, and children who have not been prescribed epinephrine. These findings are in accordance with the scientific literature [4].

The role of the allergy specialist is critical for identifying risk, reporting risk, treating comorbidities, and ensuring that a supportive, empowering, and effective management plan is in place, with medications on hand for patients and families to self-treat in cases of accidental exposure to food and other allergens [5].

Clinicians should consider these clinical risk factors when evaluating, counseling, treating, and monitoring young children with food allergies.

School canteens are a good source of information on food allergy trends in children.

Funding

The authors declare that no funding was received for the present study.

\section{Conflicts of Interest}

The authors declare that they have no conflicts of interest.

\section{Previous Presentations}

This work was presented at European Academy of Allergy and Clinical Immunology Congress, Helsinki, Finland, 17-21 June 2017.

\section{References}

1. Cabrera M. Ortiz-Menéndez JC. López-Gay D. Prevalence of food allergen-free diets in school canteens in Hortaleza district. Madrid. Pediatr Allergy Immunol. 2014 Nov;25(7):719-21.

2. Cabrera M, Ortiz-Menéndez JC, Garzón B, Barrios L. Need for Emergency Epinephrine to Treat Food Allergy Reactions in Schools in the Hortaleza District in Madrid. J Investig Allergol Clin Immunol. 2017;27(1):58-60. 
3. Smith PK, O'B Hourihane J, Lieberman P. Risk multipliers for severe food anaphylaxis. World Allergy Organ J. 2015 Nov 24;8(1):30.

4. Kim NY, Kim GR, Kim JH, Baek JH, Yoon JW, Jee HM, et al. Food allergen sensitization in young children with typical signs and symptoms of immediate type food allergies: A comparison between monosensitized and polysensitized children. Korean J Pediatr. 2015 Sep;58(9):330-5.

5. Niggemann B, Beyer K. Factors augmenting allergic reactions. Allergy. 2014;69:1582-7.

Manuscript received August 22, 2018; accepted for publication September 25, 2018.

\section{Martha Cabrera Sierra}

Servicio de Alergia

Hospital los Madroños

Carretera M-501, Km 17,9

28690 Brunete, Madrid

E-mail: marthacs65@gmail.com 